Article

\title{
Linking the Spectra of Decomposing Litter to Ecosystem Processes: Tandem Close-Range Hyperspectral Imagery and Decomposition Metrics
}

\author{
Cameron Proctor ${ }^{1, *} \mathbb{D}$, Cedelle Pereira ${ }^{2}$, Tian Jin ${ }^{3}$, Gloria $_{\text {Lim }}{ }^{3}$ and Yuhong $\mathrm{He}^{3}$ \\ 1 School of the Environment, University of Windsor, 401 Sunset Ave, Windsor, ON N9B 3P4, Canada \\ 2 Department of Geography and Planning, Queens University, 99 University Ave, \\ Kingston, ON K7L 3N6, Canada; 19cp4@queensu.ca \\ 3 Department of Geography, Geomatics and Environment, University of Toronto Mississauga, \\ 3359 Mississauga Road, Mississauga, ON L5L 1C6, Canada; cshelly.jin@mail.utoronto.ca (T.J.); \\ gloria.lim@mail.utoronto.ca (G.L.); yuhong.he@utoronto.ca (Y.H.) \\ * Correspondence: cameron.proctor@uwindsor.ca
}

check for updates

Citation: Proctor, C.; Pereira, C.; Jin, T.; Lim, G.; He, Y. Linking the Spectra of Decomposing Litter to Ecosystem Processes: Tandem Close-Range Hyperspectral Imagery and Decomposition Metrics. Remote Sens. 2022, 14, 370. https://doi.org/ $10.3390 /$ rs14020370

Academic Editor:

Roshanak Darvishzadeh

Received: 5 December 2021

Accepted: 12 January 2022

Published: 13 January 2022

Publisher's Note: MDPI stays neutral with regard to jurisdictional claims in published maps and institutional affiliations.

Copyright: (C) 2022 by the authors. Licensee MDPI, Basel, Switzerland. This article is an open access article distributed under the terms and conditions of the Creative Commons Attribution (CC BY) license (https:// creativecommons.org/licenses/by/ $4.0 /)$.

\begin{abstract}
Efforts to monitor terrestrial decomposition dynamics at broad spatial scales are hampered by the lack of a cost-effective and scalable means to track the decomposition process. Recent advances in remote sensing have enabled the simulation of litter spectra throughout decomposition for grasses in general, yet unique decomposition pathways are hypothesized to create subtly different litter spectral signatures with unique ecosystem functional significance. The objectives of this study were to improve spectra-decomposition linkages and thereby enable the more comprehensive monitoring of ecosystem processes such as nutrient and carbon cycles. Using close-range hyperspectral imaging, litter spectra and multiple decomposition metrics were concurrently monitored in four classes of naturally decayed litter under four decomposition treatments. The first principal component accounted for approximately $94 \%$ of spectral variation in the close-range imagery and was attributed to the progression of decomposition. Decomposition-induced spectral changes were moderately correlated with the leaf carbon to nitrogen ratio $\left(\mathrm{R}^{2}=0.52\right)$ and sodium hydroxide extractables $\left(R^{2}=0.45\right)$ but had no correlation with carbon dioxide flux. Temperature and humidity strongly influenced the decomposition process but did not influence spectral variability or the patterns of surface decomposition. The outcome of the study is that litter spectra are linked to important metrics of decomposition and thus remote sensing could be utilized to assess decomposition dynamics and the implications for nutrient recycling at broad spatial scales. A secondary study outcome is the need to resolve methodological challenges related to inducing unique decomposition pathways in a lab environment. Improving decomposition treatments that mimic real-world conditions of temperature, humidity, insolation, and the decomposer community will enable an improved understanding of the impacts of climatic change, which are expected to strongly affect microbially mediated decomposition.
\end{abstract}

Keywords: close-range hyperspectral imagery; litter; decomposition

\section{Introduction}

Linking the reflectance spectra of living leaves to variations in their biochemical and biophysical attributes has proven useful in monitoring ecosystem functions-for instance, assessing carbon dioxide $\left(\mathrm{CO}_{2}\right)$ sinks [1] through quantifying chlorophyll content [2] and light stress [3]. Despite biomass decomposition being a fundamental process in the life cycles of plants, coupling the spectral evolution of litter (in this study, defined as dead leaves of grasses undergoing decomposition) to ecosystem processes remains a major task [4]. Although decomposition controls nutrient availability in the soil, thus regulating primary production, there is a paucity of studies investigating the spatial-temporal dynamics of litter-borne carbon and nutrient fluxes. The deposition of litter-released compounds 
into various sinks is variable since decomposition is partially a microbially mediated activity, conducted by unique community compositions with rates regulated by abiotic and biotic factors such as climate, atmospheric $\mathrm{CO}_{2}$, and decomposer activity [5]. In addition, the fate of decomposition end-products is dependent on "phenomena" such as fire and precipitation [6,7]. For instance, in wetlands, litter can be deposited into terrestrial or aquatic systems due to wind knockdown, water levels, and leaching events $[8,9]$.

Currently, few tools are suitable for decomposition monitoring at broad spatial scales since environments such as wetlands are unamenable to field sampling, and decomposition heterogeneity occurs across large spatial scales in grasslands. The ability to monitor these decomposition pathways with a remote sensing approach would greatly improve efforts to quantify ecosystem functioning, yet spectral-decomposition linkages have only recently been quantified [10], primarily for the purposes of removing its influence from other quantities of interest. Because litter is undergoing a process of decomposition that has ecosystem function implications, we need to improve linkages between litter spectral signatures and the various decomposition pathways and their implications for litter-borne carbon and nutrient fluxes to ecosystem sinks.

Currently, there are few studies on litter spectral signatures. Investigations into litter began to help discriminate it from other ecosystem components such as soil [11] or to remove non-photosynthetic vegetation as its obfuscates retrievals of living vegetation traits [12]. Although these studies documented that litter spectral signatures are variable, the specific determinants of litter spectra and the spatial-temporal dynamics are not well understood. Changes in the leaf reflectance over time have been linked to the selective consumption of leaf structural components (e.g., cellulose, hemicellulose, lignin) [13], yet initial litter biochemicals are broken down into a variety of unique intermediates and end-products [14], and the identity of newly produced "decay pigments" is unknown. Recently, decomposition was linked to the creation of decay pigments [10], which broadly linked litter spectra to humic acid content.

Incorporating the specific absorption coefficients for decay pigments into radiative transfer models has shown a good ability to simulate the spectral evolution of monocot species from Canada [15] and improved the quantification of vegetation properties and function of mixed Mediterranean grassland canopies [16]. The application of radiative transfer modeling produced good results in both ecosystems, despite no Mediterranean species involved in the calibration dataset. However, given the variety of microbial decomposers (e.g., white rots, which selectively consume lignin, versus brown rots, which do not consume lignin) and multiple decomposition pathways (e.g., microbially mediated versus photodegradation), it is plausible that each decomposition pathway produces a unique spectral evolution and final spectral signature. As the unique spectral signatures are due to different biophysical and biochemical traits, they may have implications for ecosystem functioning and the fate of litter-borne carbon and nutrients.

One key gap in the remote sensing of decomposition is the minimal linkages between spectra and metrics of decomposition with ecosystem functional significance. The concentration of humic substances in litter is not a common ecosystem health or stress marker, and its quantification requires several phases of extraction and purification in the lab, which limits its utility. Metrics such as the litter carbon to nitrogen ratio $(\mathrm{C}: \mathrm{N})$ have strong ties to ecosystem function, as litter with a high $\mathrm{C}: \mathrm{N}$ ratio is considered poor-quality and is slower to decompose [9]. Previously, the C:N ratio was mapped using Landsat imagery and attributed to various species and their environmental conditions. Within species, changes in the $\mathrm{C}: \mathrm{N}$ ratio due solely to the progression of decomposition have yet to be established. Furthermore, other important processes, such as $\mathrm{CO}_{2}$ flux and leaching, which account for $5-40 \%$ of litter C [17], have not been investigated. Leachates are soluble in both water and $\mathrm{NaOH}$ and contain nutrients and other substances that are physiologically active. Leachates are often high in humic substances, which causes microbial immobilization and slows decomposition, especially in soil, where leachates are often deposited [18]. Litter is furthermore a considerable source of $\mathrm{CO}_{2}$ and, in mixed ecosystems of photosynthetic and 
non-photosynthetic vegetation, it obfuscates efforts to quantify photosynthetic uptake. $\mathrm{CO}_{2}$ flux should be inversely related to decomposition as microbial consumption selectively consumes labile leaf constituents, leading to a slowing of the decomposition rate over time. Collectively, these metrics of decomposition are important components influencing the carbon and nutrient cycles, and the ability to monitor their dynamics would be greatly enhanced by improved linkages to litter spectral signatures.

The utility of remote sensing is closely related to the fit between the resolution of the imaging platform (i.e., spatial, temporal, spectral, and radiometric resolution) and the phenomenon under investigation. Recent developments in the affordability of hyperspectral imagers have permitted the development of close-range hyperspectral imaging (CRHSI), which provides data of very high spatial, spectral, and temporal resolution. CRHSI is typically conducted at $0.1-2 \mathrm{~m}$ from the target and has successfully monitored small-scale processes such as leaf disease and environmental stress [19], in addition to biochemistry estimation, species identification, and phenotyping [20-22].

The objective of this study is to concurrently monitor spectral and decomposition metrics of monocot (e.g., grass) leaf litter subjected to different decomposition treatments (e.g., temperature and humidity). Spectral-decomposition linkages are further linked to key ecosystem processes such as nutrient availability, leaching, and $\mathrm{CO}_{2}$ flux. Due to the variable application of decomposition across the leaf surface, a CRHSI approach is utilized for the collection of spectral measurements. A previously developed CRHSI platform is selected based on its capability to investigate patterns in the propagation of decomposition on the leaf surface and the spectral variability that would otherwise be masked by the large sample support area of spectroradiometer-based measurements. Through linking spectra and decomposition, this study expands our current knowledge of the feasibility of a remote sensing approach for tracking decomposition dynamics and thereby helps to understand whether important carbon and nutrient transfers facilitated by decomposition are changing and their consequences.

\section{Materials and Methods}

We investigated spectral-decomposition linkages of broad relevance to ecosystem function. We used a single species, Common reed (Phragmites australis), to minimize differences in foliar chemistry [23]. This species is also locally abundant, with broad leaves, which aided in acquiring high-quality images. We collected leaves post-senescence at winter onset. We sorted the leaves into four decomposition state groups and allowed the leaves to decompose under controlled-temperature conditions. We performed non-destructive spectral and $\mathrm{CO}_{2}$ flux measurements, and destructive sodium hydroxide $(\mathrm{NaOH})$ extractions and elemental analysis on the leaves at the end of the decomposition treatment. Although decomposition produces a myriad of biochemical and biophysical changes with potentially strong linkages to spectral signatures, this investigation focused on decomposition metrics of broad relevance to ecosystem function.

\subsection{Sample Collection and Treatments}

Leaves were collected on the University of Toronto Mississauga Campus (Mississauga, ON, Canada) in November of 2019 around storm water management ponds. Random leaves were harvested over a two-day period from standing dead individuals at various heights from the surface, and thus experienced differing insolation and moisture regimes, resulting in differing maturity of decomposition. The total biomass collected (two $75 \mathrm{~L}$ garbage bags full) was air-dried and sorted visually at the leaf level, and leaves of inconsistent decay appearance, unusual markings, or those that were too fragile or thin for use were removed. The remaining set of quasi-homogenous leaf sections was subsequently sorted into four template decomposition groups (DLow, DMiddle, DMature, DExtreme) (Figure 1a) independently by three research assistants and stored in a dry plastic container prior to the decomposition treatments (Figure 1b). Each group of leaves consisted of, at minimum, 20 leaves, but the total number of leaves assigned to each group varied, with leaves 
displaying no visual evidence of decay being extremely rare, resulting in a single group for the DLow class (Table 1). Prior to any treatments, three leaves from each group were randomly selected for spectral and elemental analysis.

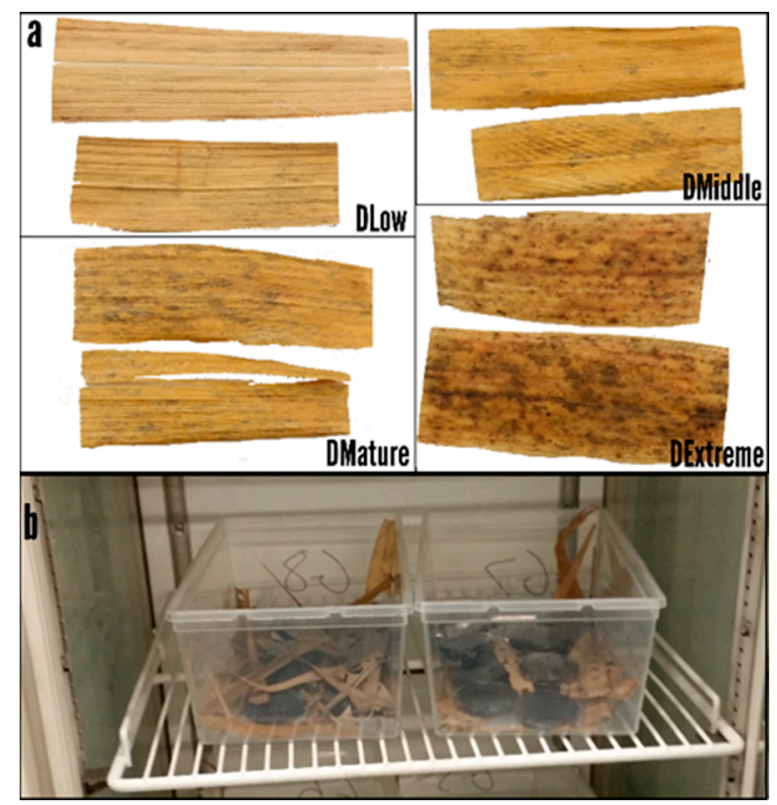

Figure 1. (a) Example leaves of the four decomposition groups; (b) litter in the incubation chamber.

Table 1. Experimental treatments and samples.

\begin{tabular}{|c|c|c|c|}
\hline Group & \# Groups & Treatment & \# Leaf Disks \\
\hline \multirow{4}{*}{ DLow } & \multirow{4}{*}{1} & $\mathrm{~L}$ & 2 \\
\hline & & $\mathrm{M}$ & $\overline{4}$ \\
\hline & & $\mathrm{HL}$ & 3 \\
\hline & & $\mathrm{HH}$ & 3 \\
\hline \multirow{4}{*}{ DMid } & \multirow{4}{*}{4} & $\mathrm{~L}$ & 11 \\
\hline & & $\mathrm{M}$ & 12 \\
\hline & & $\mathrm{HL}$ & 12 \\
\hline & & $\mathrm{HH}$ & 12 \\
\hline \multirow{4}{*}{ DMat } & \multirow{4}{*}{3} & $\mathrm{~L}$ & 6 \\
\hline & & $\mathrm{M}$ & 6 \\
\hline & & $\mathrm{HL}$ & 5 \\
\hline & & $\mathrm{HH}$ & 5 \\
\hline \multirow{4}{*}{ DExt } & \multirow{4}{*}{3} & $\mathrm{~L}$ & 5 \\
\hline & & $\mathrm{M}$ & 5 \\
\hline & & $\mathrm{HL}$ & 6 \\
\hline & & $\mathrm{HH}$ & 6 \\
\hline
\end{tabular}

These decay group templates were used to select similar leaves and prepare uniform samples for the decomposition treatment by creating discs of $5 \mathrm{~cm}$ diameter using the outside edge of a glass cylinder and a surgical knife. Three leaf discs were placed nonoverlapping into a $50 \times 9 \mathrm{~mm}$ petri dish (BD Falcon) and stored cap-off in a $20 \mathrm{~L}$ plastic storage container. The storage container was sprayed with distilled water until the leaf discs were moist, and excess water was mopped up using a fresh Kimwipe applied to the discs for a brief second. Treatments consisted of three different temperatures (L-fridge, $\mathrm{M}$-room temperature, $\mathrm{H}$-growth chamber) and two different humidity levels for the hightemperature treatment (HL-high temperature, low humidity; $\mathrm{HH}$-high temperature, high humidity). Glass beakers filled with distilled water were added to each storage box in 
the $\mathrm{HH}$ treatment, and additional moisture was added by spraying the petri dishes each week. Spectral and decomposition measurements were taken at two time periods based on visual assessment of decomposition progression, $72 \mathrm{~h}$ and 30 days after the onset of decomposition for a total of three stages of decomposition. Stage 1 represents naturally decayed leaves sorted into four groups, while Stage 2 and 3 are the naturally decayed leaves that have undergone the four decomposition treatments for different durations. Images of the original leaves and the leaf discs were collected prior to all sampling with a 24.2-megapixel D3200 digital camera (Nikon) with a standard lens. The leaf disc surface was blotted with a Kimwipe to dry the surface prior to the image collection.

\section{2. $\mathrm{CO}_{2}$ Measurements}

The $\mathrm{CO}_{2}$ flux rates from leaf discs were quantified under controlled-temperature conditions to minimize heating and cooling of the samples that would occur during sampling. Petri dishes containing the leaf discs were stored capped for three hours at $45^{\circ} \mathrm{C}$ prior to $\mathrm{CO}_{2}$ flux measurements in a low-temperature oven to allow the samples to equilibrate. Leaf disc sampling was randomly stratified between treatments to minimize biases in sample collection. The pre-sampling protocol involved drying both sides of the leaf discs with a fresh Kimwipe, collecting a macro photograph with a 24.2-megapixel D3200 digital camera (Nikon, Tokyo, Japan), and storing it in a soda-lime-lined box prior to analysis. Flux rates of the samples were quantified using an EGM-4 (PP systems) setup in a pumped closed loop with a custom flow-through chamber that fit on top of the petri dishes (water seal) to record the increase in $\mathrm{CO}_{2}$ over time. The chamber $\mathrm{CO}_{2}$ concentration was recorded every two seconds for three minutes, with rates calculated after a 30 s equilibrium as the increase in $\mathrm{CO}_{2}$ concentration over time. Every ten samples, a control sample was run using a $\mathrm{CO}_{2}$ scrubber (soda-lime-packed syringe) to ensure that the instrument was in proper working condition.

\subsection{Spectral Measurements}

Spectral measurements were taken by a custom CRHSI platform [24] equipped with a Micro-A series imager (Headwall Photonics, Bolton, MA, USA) that captured 325 bands between 400 and $1000 \mathrm{~nm}$ (Figure 2). For imagery collection, petri dishes (FisherScientific, Hampton, NH, USA) were arranged in $2 \times 8$ columns on the linear stage platform. A Spectralon white reference (Labsphere, North Sutton, NH, USA) was placed at the same height as the leaf discs. Illumination was provided by two DCR III DC regulated light boxes (SCHOTT, New York, USA) equipped with a $150 \mathrm{~W}$ halogen bulb (USHIO, Tokyo, Japan), mounted $15 \mathrm{~cm}$ above the scan area and pointing forwards and backwards at a $45^{\circ}$ angle to the scan area. The imager and light sources were locked in position, while the sample was moved through the scan area during the imagery acquisition by a servo motor-controlled 5' linear slide (Velmex, New York, USA). Based on the imager height and a $40 \mathrm{~ms}$ exposure per scan line, the speed of the sample stage was adjusted to align the size of the across- and along-track area for an image with an approximately $0.12 \mathrm{~mm}$ pixel size. Post-processing involved converting raw radiance values to reflectance using the ratio of sample to white reference radiance per scan column to account for minor variation in across-track illumination. Reflectance between 435 and $805 \mathrm{~nm}$ was utilized in this analysis due to low radiance output from the line lights outside these regions. Non-leaf disc pixels were masked and removed from the imagery.

A data set of individual pixel spectra was derived from all imagery (initial fieldcollected samples sorted visually, leaf discs after the onset of decomposition, leaf discs at the end of the decomposition treatment) based on approximately 600,000 randomly selected pixels (approximately 15\% of the pixels of a leaf disc). Reflectance spectra are either presented for individual pixels, or the average spectra of all the random points belonging to each leaf disc, or all leaf discs belonging to a decomposition group. Per-pixel reflectance values ( 26 bands at $13 \mathrm{~nm}$ spacing between 435 and $805 \mathrm{~nm}$ ) were decomposed into lowerdimensional space using $R$ ( $R$ statistical software v4.0.2.) for principal component analysis 
(prcomp function using a correlation matrix). The derived rotation parameters were used to predict the coordinates of the average leaf disc reflectance of each individual leaf disc.

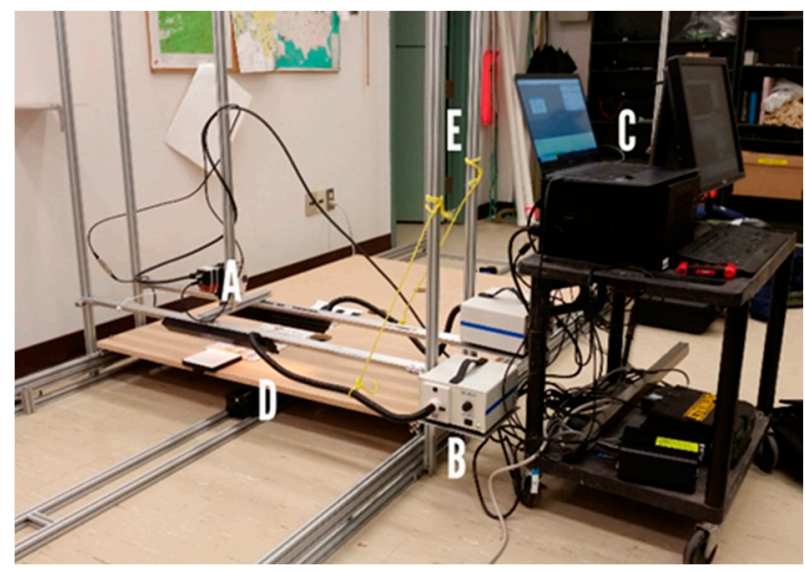

Figure 2. Close-range hyperspectral imaging platform. (A) Headwall imager, (B) light sources, (C) data processing unit, (D) linear stage, (E) frame.

\section{4. $\mathrm{NaOH}$ Extractions}

At the end of the decomposition treatments and post spectral and $\mathrm{CO}_{2}$ flux measurements, a hole punch was used to remove two sections of each of the three leaf discs per sample $(n=6)$ for $\mathrm{NaOH}$ extractions. The sub-samples were placed in metal weigh trays and dried in an oven at $120{ }^{\circ} \mathrm{C}$ for $24 \mathrm{~h}$ and weighed on an analytical balance. The holepunched discs were added to a centrifuge tube with $50 \mathrm{~mL}$ of $1 \mathrm{M} \mathrm{NaOH}$ and left to extract for $24 \mathrm{~h}$. After extraction, $2 \mathrm{~mL}$ was pipetted into a quartz cuvette, and its absorbance was scanned from 200 to $700 \mathrm{~nm}$ using a GENESYS 10S UV-VIS spectrometer (Thermo Scientific, Waltham, MA, USA).

\subsection{Elemental Analysis}

The remaining dried leaf material was ground in a TissueLyser II bead mill (QIAGEN, Hilden, Germany) for two minutes until formed into a powder for elemental analysis on a ECS 4010 CHNS-O Analyzer (Costech Analytical, Valencia, CA, USA). Approximately $3 \mathrm{mg}$ of powdered sample was wrapped in tin and analyzed for $\mathrm{C}$ and $\mathrm{N}$ content in reference to EDTA calibration standards. The $\mathrm{C}: \mathrm{N}$ ratio was derived from the percentage mass measurements.

\section{Results}

\subsection{Litter and Decomposition Spectra}

At the pixel level, the CRHSI of the decaying leaf disc did not feature prominent peaks, valleys, or sills in the VIS-NIR region. Instead, reflectance increased gradually from the VIS to the NIR, similar to previous CRHSI studies [25]. As decomposition continued, the color tones of leaves increasingly darkened, and reflectance at longer wavelengths notably declined relative to other wavelengths. Individual decay spots on leaf discs could be clearly resolved in the imagery (Figure 3a), with the reflectance of these spots considerably reduced, even in leaf discs that were highly decayed (Figure 3b). Decay spots appeared to have a similar spectrum regardless of their appearance on imagery collected prior to the decomposition treatment, at either of the two time periods of the decomposition treatment. In all cases, the treatment increased the area of the leaf with visible decay, yet the resulting decay patterns were inconsistent (Figure 3c). Decay spots appeared as small spots, larger patches, parallel lines, and speckles, creating a "salt and pepper" pattern. These patterns often mimicked those in the initial template decay groups, but differing patterns also manifested despite both receiving the same decomposition conditions. No patterns in the CRHSI of decomposition were evident in either the naturally occurring litter 
or the leaf discs. These results were not unexpected as decay is a heterogeneous process that is significantly influenced by the surface area exposed to decomposers, microclimatic influences, and the physical integrity of the leaf surface and whether weathering cracks allow entry into the leaf interior.

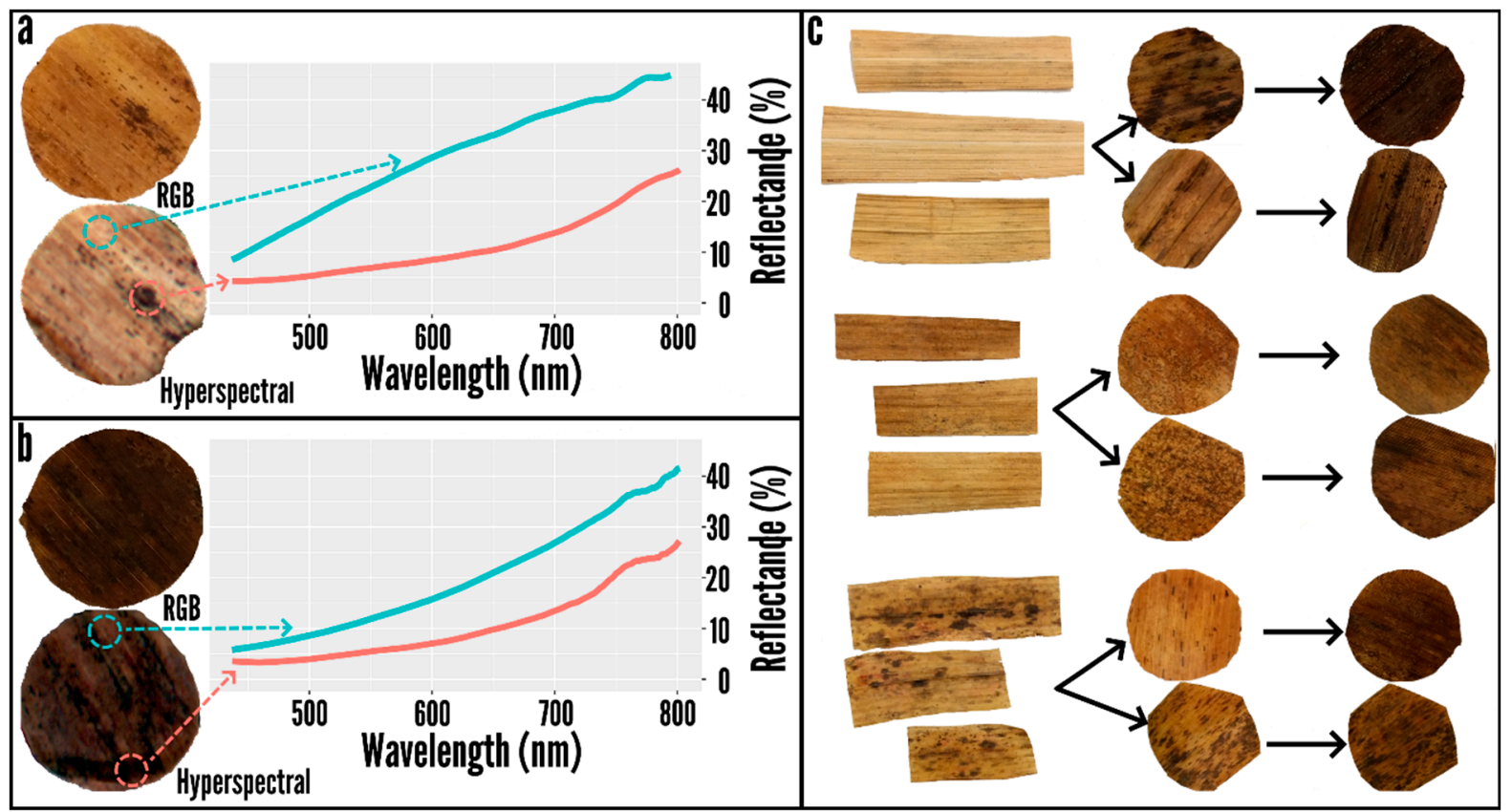

Figure 3. Progression of decay as evidenced by photographs and CRHSI of leaf discs. (a) Reflectance of individual pixels in CRHSI of a DMid leaf disc at Stage 1 ; (b) reflectance of the same leaf disc at Stage 3; (c) photographs of initial leaf groups (top to bottom: DLow, DMid, DExtreme) and progression of decomposition of the same leaf disc at Stage 2 and Stage 3.

Although patterns in decomposition on leaf surfaces were variable, spectral changes in leaves undergoing decomposition were more straightforward. The average spectral signature of the initial decay groups indicated a similar spectral change as that quantified at the pixel level. Based on the average spectra for all pixels belonging to the leaf discs of each decomposition group, the decomposition group with minimal visible evidence of decay (DLow) had the highest reflectance for all wavelengths relative to the other decomposition groups, which showed a trend of decreasing reflectance with the maturity of decomposition (Figure 4a). However, individual pixels of the DLow group had spectral signatures similar to more advanced decomposition groups. Only in one small-wavelength region did the spectral variability (one standard deviation) of DLow and DMid overlap slightly (Figure 4a), yet it would be rare for pixels of DLow and DMat to have similar spectra. Spectral variability generally increased positively with wavelength, in part because, as decay progresses, reflectance at shorter wavelengths decreases, foremost due to the strong absorption of decay pigments.

Principal component analysis revealed that approximately $94 \%$ of the variance in the per-pixel reflectance could be explained by the first principal component, which was attributed to decomposition-induced spectral changes (Figure $4 \mathrm{~b}$ ). The contribution of each wavelength to the first principal component was approximately equal, although there was a moderate decline ( $40 \%$ of the top contributing wavelength) in the contribution from shorter wavelengths such as $431 \mathrm{~nm}$ and a minor drop in contribution at $668 \mathrm{~nm}$. Reflectance at 435,802 , and $668 \mathrm{~nm}$ highlighted the strongest contributing wavelengths of the second and third principal components. The long tail in the upper right corner of the PCA analysis related to the second component and linked to senescent vegetation, as evidenced by the close association with the DLow group. Within the initial decay groups, there were considerable differences in the second principal component, but a clear trend of increasing 
decay towards negative values of the first principal component. Stage 2 and 3 leaf discs reflected the same trend of narrowing spectral variability as decomposition progressed (Figure 4b).

a)

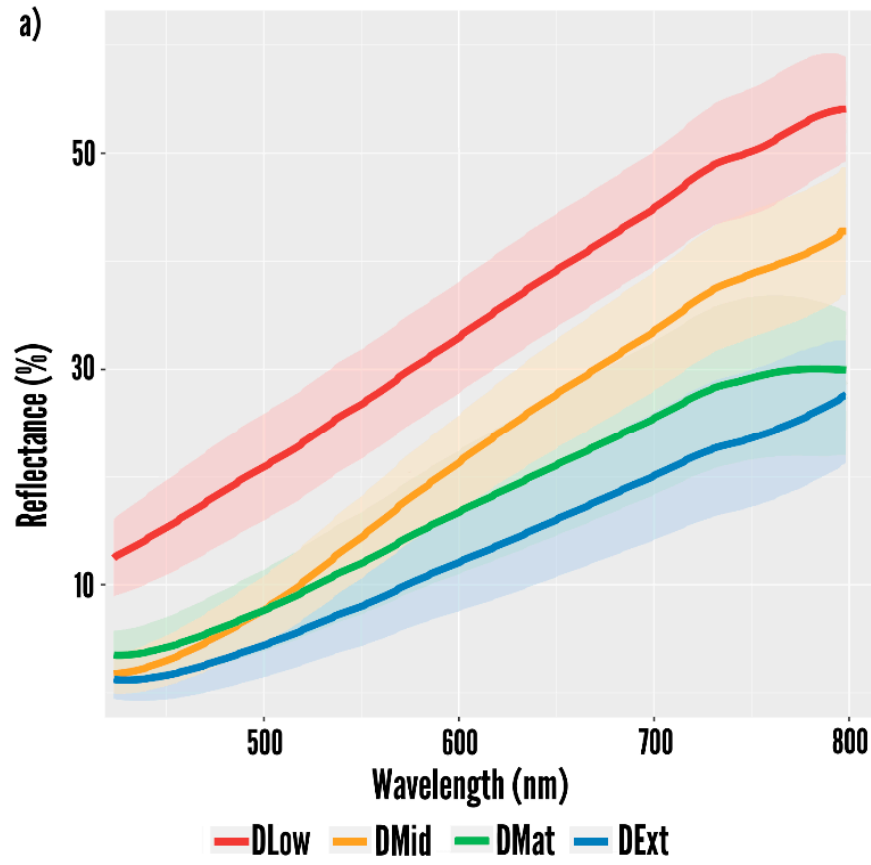

b)

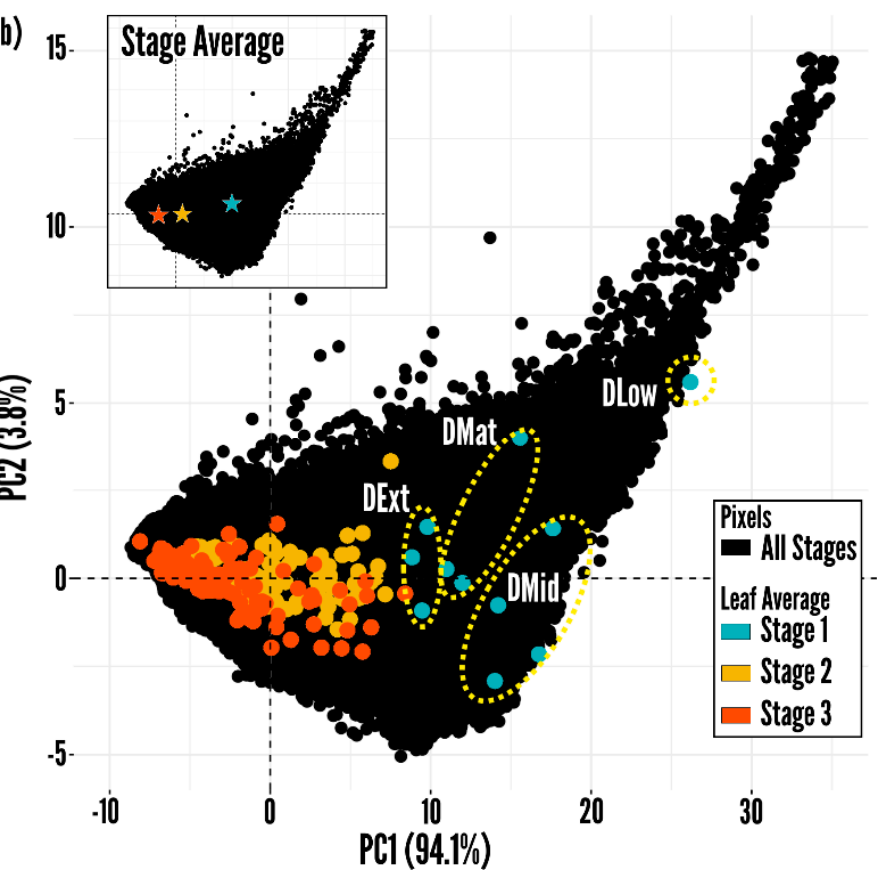

Figure 4. (a) Average reflectance (line) and standard deviation (ribbon) of all pixels for all leaves per decay group at Stage 1 collected by CRHSI; (b) first and second principal components of approximately 600,000 randomly selected pixels as black dots. Colored dots are the average spectra of each leaf disc. The yellow ellipses circle all leaves belonging to the same decomposition group, with the group name indicated in white text. The top left inset shows the predicted principal analysis coordinates for the average spectra of all pixels from each stage (all decomposition groups).

\subsection{Decomposition Treatment Effects}

Embedded temperature and humidity sensors recorded the average conditions for each treatment (Table 2). Exposure to higher temperatures, on average, increased the degree of leaf disc decomposition over the course of the treatment, regardless of the initial decay group. Pairwise $t$-tests indicated that the mean first principal component of each group was statistically significant, except for the Stage $3 \mathrm{M}$ and HL treatment groups, which could not be distinguished as unique groups (Figure 5). The higher humidity in the $\mathrm{HH}$ group versus the HL group further encouraged decomposition. Between the decomposition status of the Stage 1 group and Stage 3, there was little overlap. However, between the treatment groups, there was a moderate degree of similarity, even between the low- and high-temperature treatments. One leaf disc in the high-temperature treatment had a similar first principal component value to the median value in the low-temperature treatment group. Interestingly, the low-temperature treatment group had the highest variability in decomposition, which was partially attributed to there being many leaf discs, with the minimal progression of decomposition between Stage 2 and Stage 3.

Table 2. Average environmental conditions per treatment.

\begin{tabular}{ccc}
\hline Treatment & Relative Humidity (\%) & Temperature $\left({ }^{\circ} \mathbf{C}\right)$ \\
\hline Low & 65.3 & 6.5 \\
Medium & 48.4 & 20.4 \\
High & 31.1 & 29.8 \\
\hline
\end{tabular}


The low-temperature treatment further had a statistically significant mean in the second principal component $(t$-test $p<0.05)$ compared to the middle and hot treatments. The average second principal component value was statistically significant between all treatments $($ Low $=-0.66 \mid$ Middle $=-0.09 \mid$ High $=0.19)$, which was likely related to the maturity of decomposition. Aside from slowing decomposition, temperature and humidity had little effect.

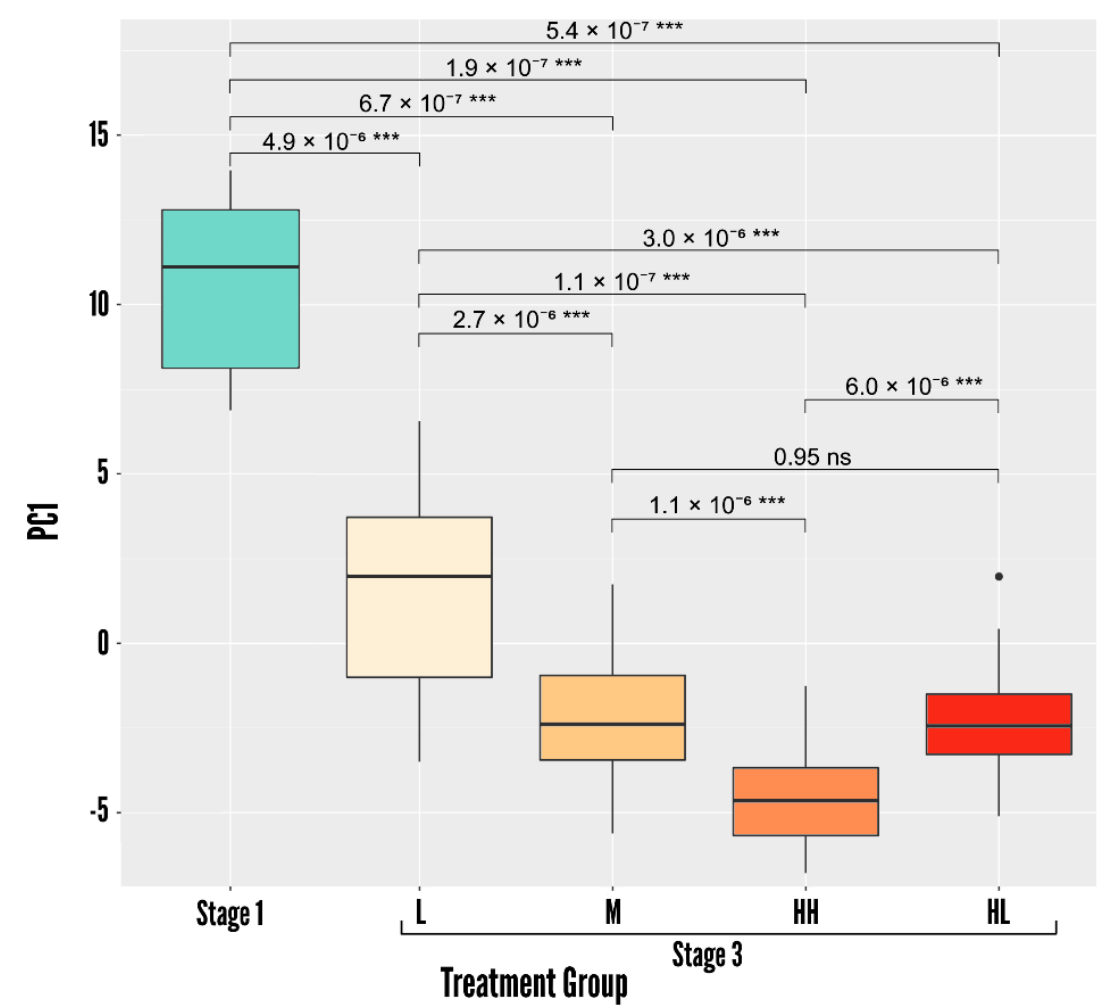

Figure 5. Boxplot of the first principal component value of image pixels at Stage 1 and 3 by treatment group. Bars between treatment groups show the pairwise $t$-test $p$-value and indicate the significance of the difference in means $(* * *=p$-value $<0.01$, ns $=$ not significant).

\subsection{Spectra and Decomposition Metrics}

The spectra of decomposing leaf discs (the predicted first principal component based on the average spectra of all pixels per leaf discs) were moderately correlated with several decomposition metrics, including the C:N ratio (Pearson's correlation $=0.55$ ) (Figure 6). Decomposition generally lowered the $\mathrm{C}: \mathrm{N}$ ratio of the leaf discs. The average C:N ratio of the $\mathrm{HH}$ group was $26.1 \pm 9.0$, which was close to half that of the LH treatment group, with $45.2 \pm 13.2$. Results of $t$-tests between each treatment group indicated that certain treatment groups had statistically significant differences in the $\mathrm{C}: \mathrm{N}$ ratio (Table 3). For instance, the LH group was statistically different from all other groups, while the HH group was statistically different from LH and had a $p$-value at the cusp of a statistically significant $p$-value (generally accepted as $p<0.05$ ) with the MH and HL treatments. The negative relationship between decomposition and the $\mathrm{C}: \mathrm{N}$ ratio was consistent between all four decay groups and treatments. 


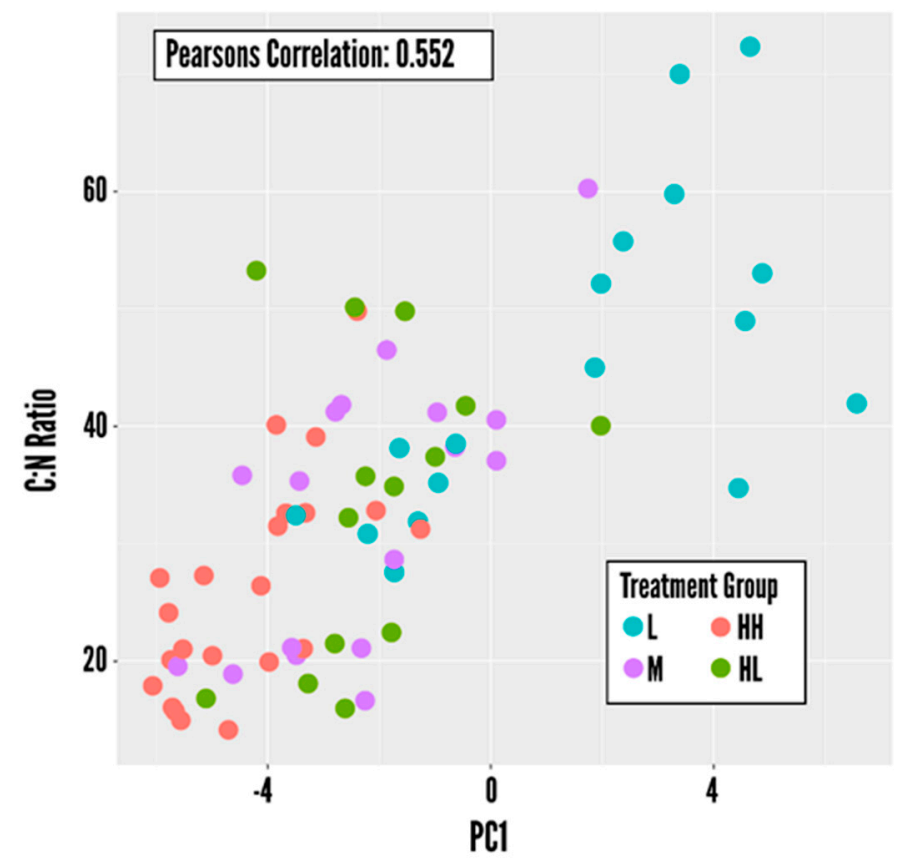

Figure 6. Relationship between the Stage 3 average leaf disc spectra (predicted first principal component) and C:N ratio.

Table 3. C:N ratio $t$-test results by treatment group.

\begin{tabular}{ccc}
\hline Group1 & Group2 & $p$-Value \\
\hline HH & HL & 0.0732 \\
HH & LH & 0.00000525 \\
HL & LH & 0.00852 \\
HH & MH & 0.0716 \\
HL & MH & 0.932 \\
LH & MH & 0.00447 \\
\hline
\end{tabular}

A similar negative relationship was found for $\mathrm{PC} 1$ and $\mathrm{NaOH}$ extracts, with the strongest correlation with the UV absorbance ratios of 360/450 nm (Pearson's correlation $=-0.43$ ). Other UV absorbance ratios involving bands in the $200-300 \mathrm{~nm}$ region produced slightly weaker correlations (Pearson's correlation ranging from -0.38 to -0.41 ). Although absorbance at wavelengths between 227 and $280 \mathrm{~nm}$ is often associated with changes in the structure of decomposition products, the variance in this region was relatively large compared to absorbance at 360 and $450 \mathrm{~nm}$. For example, comparing the absorbance of $\mathrm{NaOH}$ extracts of the least and most decayed Stage 3 leaf discs showed a less pronounced dip at $270 \mathrm{~nm}$ (absorbance of $0.65 \mathrm{vs}$. 0.61), lower absorbance between 280 and $370 \mathrm{~nm}$ (average absorbance in this region of $0.51 \mathrm{vs.} 0.54$ ), and higher absorbance between 370 and $700 \mathrm{~nm}$ (average absorbance in this region of 0.054 vs. 0.041) (Figure 7). However, $t$-test results at even the largest gap (i.e., $270 \mathrm{~nm}$ ) did not suggest that these were statistically significant differences. Despite the challenges in selecting absorbance wavelengths, there were moderate correlations between $\mathrm{NaOH}$ extracts and average leaf disc spectra.

In contrast, $\mathrm{CO}_{2}$ flux is an instantaneous metric that does depend on the historicity of decomposition (e.g., preferential consumption of labile compounds reduces the quantity and quality of litter and thereby retards microbially mediated decomposition [16]) but is sensitive to current environmental conditions, which can drive process rates many times higher than baseline rates [26]. As such, no relation could be found between litter spectra and $\mathrm{CO}_{2}$ flux rates for pooled samples or any sub-group. Flux rates in Stage 2 were larger than Stage 3 and statistically significant (Stage 2: mean 0.75 I coefficient of variation 
0.44 I range $0.19-1.77 \mathrm{ppm} / \mathrm{s}$, versus Stage 3: mean 0.27 I coefficient of variation 0.48 I range 0.01-0.64 ppm/s). At Stage 3, the four decay groups further had increasing rates with decay stage (DExt $>$ DMat $>$ DMid $>$ DLow). However, there was considerable overlap in $\mathrm{CO}_{2}$ flux rates and only the DLow treatment could be distinguished as a unique group ( $t$-test $p<0.05)$. The temporal trend in $\mathrm{CO}_{2}$ evolution was biphasic in that rates initially increased with the liberation of labile biomolecules at the onset of decomposition, with rates slowly decreasing over time as recalcitrant biomolecules became the dominant fraction [27].

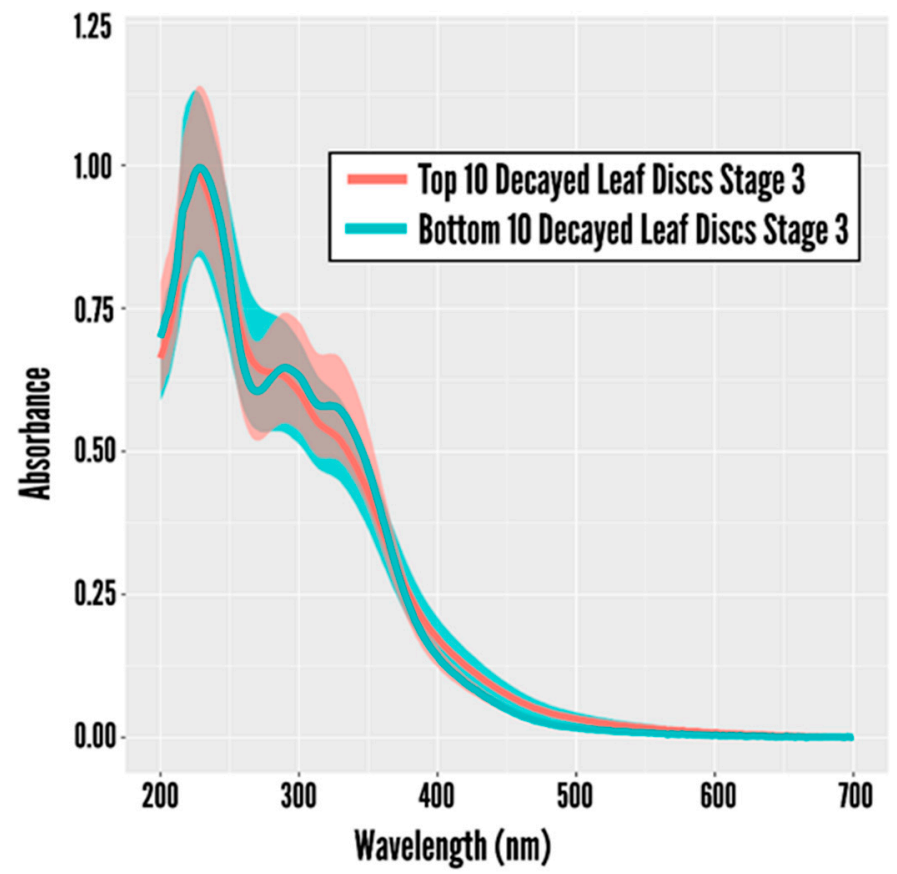

Figure 7. UV spectroscopy of $\mathrm{NaOH}$ extracts for the 10 leaf discs with the highest and lowest first principal component values (e.g., the most and least decayed).

\section{Discussion}

Senescence begins with the plant absorbing chlorophyll and other biomolecules from its leaves, with the subsequent production of pigments such as carotenoids, which aid the transfer out of the leaves by providing a shielding role for sensitive molecules (e.g., chlorophyll) [23]. However, the efficacy of the sequestering process is not absolute, and a myriad of biochemicals that served for photosynthesis, predator protection, leaf structure, etc., remain within the leaf and undergo oxidation. The resultant mix is subject to microbial activities, with preferential decomposition of labile biomolecules. Thus, this complex process is liable to expose and transform the leaf remains through different decomposition pathways depending on the microflora present. The results of the PCA analysis suggest that naturally decayed litter features some spectral variability, yet, post decomposition treatment, the spectral variability is reduced, especially as decay progresses into the later stages. At the onset of the experiment, the second principal component had the largest variability. Over the decomposition treatment, as the leaf discs shifted to more extreme decomposition stages and the first principal component value consequently shifted to lower values, the variability in the second principal component was reduced. As decomposition produces pigments that are strong absorbers, decay pigments dominate the reflectance and tend to mask absorbance from other biomolecules. The group of litter decomposed to the largest extent in the high-temperature and humidity group had minimal spectral variability, with the spectra dominated by absorbance due to humic substances [28]. These findings suggest that the end-products of decomposition have strong absorption characteristics that mask the signatures of other elements, and/or the effects of decomposition occur on the leaf surface and thereby mask internal spectra signatures. 
While this study indicates that decomposition spectral signatures have minimal variability and straightforward evolution, these results are strongly dependent on the conditions of the decomposition treatment. The indoor growth conditions likely inadvertently allowed certain decomposer species to colonize and proliferate, thereby altering the biomolecules targeted for consumption and the final decomposition spectra. An example of this phenomenon can be observed in wood decay and the different types of rot (brown rot vs. white rot), which preferentially break down the hemicellulose and cellulose or the lignin, resulting in brown or white end-products. Furthermore, soft rots can colonize wood under conditions that are unfavorable for either white or brown rots, reinforcing the notion of multiple decomposition pathways controlled by environmental conditions [29]. In addition to decay under real-world conditions likely being mediated by a wider consortium of decomposers, plant litter is exposed to ultraviolet (UV) radiation, which causes the direct (photochemical mineralization) and indirect (photofacilitation) breakdown of organic matter [30]. In contrast to microbial decomposition, photodegradation produces a "bleached" appearance and the loss of color [31]. As microbial and photodegradation are concurrent processes, incorporating UV radiation into the methodological design is essential for understanding the diversity of decaying leaf spectra. These results suggest that field studies manipulating the environmental conditions (e.g., temperature, moisture, UV light, etc.) to encourage unique decomposition pathways may be required. Construction of a robust litter optical properties database associating variation in litter biophysical and biochemical properties due to the onset and maturation of competing decomposition pathways with litter spectra is the next step in the development of the remote sensing of decomposition. Previously, these types of databases provided the foundation for the development of radiative transfer models for the retrieval of photosynthetic vegetation traits, and, therefore, the same approach can be applied to non-photosynthetic vegetation.

Another methodological limitation is the inability to accurately measure water-soluble compounds due to leaching. A slightly yellow-brownish tinged liquid occasionally accumulated in the petri dishes and was removed prior to imaging and $\mathrm{NaOH}$ extraction. The anecdotal observations suggest that hydrolyzation may have leached some C compounds, and leaching was stronger in further decomposed leaf discs, and this effect occurred prior to their quantification by $\mathrm{NaOH}$ extraction. In terms of ecological significance, litter leaching can constitute a significant fraction of the nutrient release [32]. Further methodological refinement to simulate or capture this loss of $\mathrm{C}$ in relation to rainfall and subsequent spectral changes is needed. Understanding how the leaching process affects the spectra and flow of physiologically active compounds is an essential component of decomposition dynamics and their ecological effects. Future studies may need to collect leachates over the decomposition process and profile their carbon and nutrient content in addition to their concentration of other compounds such as phenolics, which have been linked to the depression of plant and soil microbial community function.

In remote sensing, encountering scale dependency in the quantification of processes, structures, and function is not unusual. To this end, several monitoring platforms with trade-offs in spatial, temporal, and spectral resolution have been developed to optimize the retrieval of vegetation traits and hopefully up- and downscale as needed for specific applications. The close-range approach presented has shown good performance in monitoring at fine spatial scales the progression of decomposition and demonstrating that, at several stages, the leaf surface may simultaneously contain areas with minimal decomposition and patches featuring considerable decay pigments. Whether the spatial-temporal pattern of microbial consumption of leaf litter has any spectral or ecological significance requires further explanation by a multi-scale monitoring approach. Since many popular radiative transfer models assume a uniform distribution of absorbing pigments along the leaf surface and within the vertical profile, further investigation by the close-range approach of the heterogeneous distribution of decay pigments during the decomposition process is crucial for understanding the upscaling challenges. 
Although we can expect spectral measurements at the leaf level to be similar regardless of distance (assuming that the single leaf is within the sensor's field of view), canopy-level spectral signatures introduce several factors that will alter the behavior of the spectral signatures between close-range, drone, airplane, and satellite imagery. Foremost, the geometry of litter canopies is more complex than the flat leaf discs measured in this study. Leaves anchored to the plant at greater distances from the surface experience microclimatic differences (e.g., sunlight and humidity), which alter their decomposition trajectories. It is unclear how these important canopy factors influence the accurate retrieval of leaf-level traits and whether quantifying decomposition beyond an assessment of decomposition state yields insights into important processes such as litter leaching and nutrient cycling. Advances in the radiative transfer modeling of litter have shown improvements in the retrieval of energy, water, and carbon fluxes [16], suggesting a renewed need for spatialtemporally resolved data sets of decomposition. While remote sensing applications of litter monitoring are likely at broad scales, this study has shown that close-range imaging is an effective tool that provides complementary information.

Overall, this research demonstrates that linking spectra to metrics of decomposition and understanding their ecological significance is challenging. Unlike living vegetation, the concepts of health and stress are more complicated to operationalize due to the microscale nature of the decomposition process and the disconnect between "average" spectra and microbial activity. Ironically, the prevailing evidence suggests that decomposition spectra are more constrained than hypothesized, which limits the ability to discern unique decomposition pathways, but also enables confidence in the science of monitoring decomposition dynamics. This study has demonstrated the efficacy of hyperspectral remote sensing to assess the state of decomposition, which has considerable importance in many ecosystem functions.

\section{Conclusions}

The hypothesis that litter spectral signatures were dependent on the decomposition treatment and that litter spectra had linkages to important metrics relevant for ecosystem processing of carbon and nutrients was partially validated. Litter spectra-decomposition linkages had previously been limited to humic substances, and this study extended these linkages to the $\mathrm{C}: \mathrm{N}$ ratio and $\mathrm{NaOH}$ extractable pigments. However, the decomposition treatments appeared to only delay litter decay along a single decomposition pathway and no unique decomposition spectra were produced. The study outcome cannot indicate whether alternative decomposition pathways such as photodegradation or microbial decomposition by other types of rot produce unique litter biochemical or biophysical traits with implications for ecosystem processes. The study does improve spectra-decomposition linkages and thereby forms the prerequisites for a remote-sensing-based program to monitor decompositional processes. Such a program would enable a more comprehensive understanding of the carbon and nutrient cycles and their responses to recent climatic changes in temperature and precipitation, which are often highlighted as the main drivers of decomposition rates and the flow of decomposition-borne products to various pools. Furthermore, this study demonstrates that CRHSI technologies are a valuable tool for monitoring the progression of decomposition at fine spatial resolution.

Author Contributions: Conceptualization, C.P. (Cameron Proctor); investigation, C.P. (Cedelle Pereira), G.L. and T.J.; methodology, C.P. (Cameron Proctor); formal analysis, C.P. (Cameron Proctor); writing-original draft preparation, C.P. (Cameron Proctor); writing-review and editing, C.P. (Cameron Proctor) and Y.H.; visualization, C.P. (Cameron Proctor); project administration, C.P. (Cameron Proctor); funding acquisition, C.P. (Cedelle Pereira). All authors have read and agreed to the published version of the manuscript.

Funding: This work is supported by NSERC Discovery Grant RGPIN-386183 and CFI/ORF \#26492 to Yuhong He and the UTM Undergraduate Research Grant in the Department of Geography, Geomatics and Environment at the University of Toronto Mississauga. 


\section{Institutional Review Board Statement: Not applicable.}

Informed Consent Statement: Not applicable.

Data Availability Statement: Publicly available datasets were analyzed in this study. These data can be found here: https:/ / github.com/drproctorWindsor/CloseRangeHyperspectalDecomposition (accessed on 30 August 2021).

Acknowledgments: We gladly thank the Remote Sensing and Spatial Ecosystem Modeling laboratory and Yuhong He for the use of the close-range hyperspectral imaging platform, Phil Rudz for his support and technical expertise, and the Department of Geography, Geomatics and Environment for the use of their spaces.

Conflicts of Interest: The authors declare no conflict of interest.

\section{References}

1. Sitch, S.; Friedlingstein, P.; Gruber, N.; Jones, S.D.; Murray-Tortarolo, G.; Ahlström, A.; Doney, S.C.; Graven, H.; Heinze, C.; Huntingford, C.; et al. Recent trends and drivers of regional sources and sinks of carbon dioxide. Biogeosciences 2015, 12, 653-679. [CrossRef]

2. $\quad$ Feret, J.B.; François, C.; Asner, G.P.; Gitelson, A.A.; Martin, R.E.; Bidel, L.P.; Ustin, S.L.; Le Maire, G.; Jacquemoud, S. PROSPECT-4 and 5: Advances in the leaf optical properties model separating photosynthetic pigments. Remote Sens. Environ. 2008, 112, 3030-3043. [CrossRef]

3. Gamon, J.A.; Peñuelas, J.; Field, C.B. A narrow-waveband spectral index that tracks diurnal changes in photosynthetic efficiency. Remote Sens. Environ. 1992, 41, 35-44. [CrossRef]

4. Facelli, J.; Pickett, S.T.A. Plant litter: Its dynamics and effects on plant community structure. Bot. Rev. 1991, 57, 1-32. [CrossRef]

5. Sabetta, L.; Zaccarelli, N.; Mancinelli, G.; Mandrone, S.; Salvatori, R.; Costantini, M.L.; Zurlini, G.; Rossi, L. Mapping litter decomposition by remote-detected indicators. Ann. Geophys. Ann. Geofis. 2009, 49, 219-226. [CrossRef]

6. Austin, A.T.; Vitousek, P.M. Precipitation, decomposition and litter decomposability of Metrosideros polymorpha in native forests on Hawai'i. J. Ecol. 2000, 88, 129-138. [CrossRef]

7. Fynn, R.; Haynes, R.; O'Connor, T. Burning causes long-term changes in soil organic matter content of a South African grassland. Soil Biol. Biochem. 2003, 35, 677-687. [CrossRef]

8. Wallis, E.; Raulings, E. Relationship between water regime and hummock-building by Melaleuca ericifolia and Phragmites australis in a brackish wetland. Aquat. Bot. 2011, 95, 182-188. [CrossRef]

9. Yang, R.; Dong, J.; Li, C.; Wang, L.; Quan, Q.; Liu, J. The decomposition process and nutrient release of invasive plant litter regulated by nutrient enrichment and water level change. PLoS ONE 2021, 16, e0250880. [CrossRef]

10. Proctor, C.; Lu, B.; He, Y. Determining the absorption coefficients of decay pigments in decomposing monocots. Remote Sens. Environ. 2017, 199, 137-153. [CrossRef]

11. Nagler, P.L.; Daughtry, C.S.T.; Goward, S.N. Plant Litter and Soil Reflectance. Remote Sens. Environ. 2000, 71, 207-215. [CrossRef]

12. Guerschman, J.P.; Hill, M.; Renzullo, L.J.; Barrett, D.J.; Marks, A.S.; Botha, E.J. Estimating fractional cover of photosynthetic vegetation, non-photosynthetic vegetation and bare soil in the Australian tropical savanna region upscaling the EO-1 Hyperion and MODIS sensors. Remote Sens. Environ. 2009, 113, 928-945. [CrossRef]

13. Daughtry, C.S.; Serbin, G.; Reeves, J.; Doraiswamy, P.C.; Hunt, J.E.R. Spectral Reflectance of Wheat Residue during Decomposition and Remotely Sensed Estimates of Residue Cover. Remote Sens. 2010, 2, 416-431. [CrossRef]

14. Janusz, G.; Pawlik, A.; Sulej, J.; Świderska-Burek, U.; Jarosz-Wilkolazka, A.; Paszczyński, A. Lignin degradation: Microorganisms, enzymes involved, genomes analysis and evolution. FEMS Microbiol. Rev. 2017, 41, 941-962. [CrossRef] [PubMed]

15. Lu, B.; Proctor, C.; He, Y. Investigating different versions of PROSPECT and PROSAIL for estimating spectral and biophysical properties of photosynthetic and non-photosynthetic vegetation in mixed grasslands. GIScience Remote Sens. 2021, 58, 354-371. [CrossRef]

16. Pacheco-Labrador, J.; El-Madany, T.S.; van der Tol, C.; Martin, M.P.; Gonzalez-Cascon, R.; Perez-Priego, O.; Guan, J.; Moreno, G.; Carrara, A.; Reichstein, M.; et al. senSCOPE: Modeling mixed canopies combining green and brown senesced leaves. Evaluation in a Mediterranean Grassland. Remote Sens. Environ. 2021, 257, 112352. [CrossRef]

17. Krishna, M.P.; Mohan, M. Litter decomposition in forest ecosystems: A review. Energy Ecol. Environ. 2017, 2, 236-249. [CrossRef]

18. Strickland, M.S.; Osburn, E.; Lauber, C.; Fierer, N.; Bradford, M.A. Litter quality is in the eye of the beholder: Initial decomposition rates as a function of inoculum characteristics. Funct. Ecol. 2009, 23, 627-636. [CrossRef]

19. Mishra, P.; Asaari, M.S.M.; Herrero-Langreo, A.; Lohumi, S.; Diezma, B.; Scheunders, P. Close range hyperspectral imaging of plants: A review. Biosyst. Eng. 2017, 164, 49-67. [CrossRef]

20. Rascher, U.; Blossfeld, S.; Fiorani, F.; Jahnke, S.; Jansen, M.; Kuhn, A.J.; Matsubara, S.; Märtin, L.L.A.; Merchant, A.; Metzner, R.; et al. Non-invasive approaches for phenotyping of enhanced performance traits in bean. Funct. Plant Biol. 2011, 38, 968-983. [CrossRef]

21. Bergsträsser, S.; Fanourakis, D.; Schmittgen, S.; Cendrero-Mateo, M.P.; Jansen, M.; Scharr, H.; Rascher, U. HyperART: Non-invasive quantification of leaf traits using hyperspectral absorption-reflectance-transmittance imaging. Plant Methods 2015, 11, 1. [CrossRef] 
22. Mahlein, A.-K.; Kuska, M.; Behmann, J.; Polder, G.; Walter, A. Hyperspectral Sensors and Imaging Technologies in Phytopathology: State of the Art. Annu. Rev. Phytopathol. 2018, 56, 535-558. [CrossRef] [PubMed]

23. Matile, P. Biochemistry of Indian summer: Physiology of autumnal leaf coloration. Exp. Gerontol. 2000, 35, 145-158. [CrossRef]

24. Proctor, C.; Dao, P.D.; He, Y. Close-range, heavy-duty hyperspectral imaging for tracking drought impacts using the PROCOSINE model. J. Quant. Spectrosc. Radiat. Transf. 2021, 263, 107528. [CrossRef]

25. Morel, J.; Jay, S.; Féret, J.-B.; Bakache, A.; Bendoula, R.; Carreel, F.; Gorretta, N. Exploring the potential of PROCOSINE and close-range hyperspectral imaging to study the effects of fungal diseases on leaf physiology. Sci. Rep. 2018, 8, 15933. [CrossRef]

26. Kuzyakov, Y.; Blagodatskaya, E. Microbial hotspots and hot moments in soil: Concept \& review. Soil Biol. Biochem. 2015, 83, 184-199. [CrossRef]

27. Cha, S.; Chae, H.-M.; Lee, S.-H.; Shim, J.-K. Effect of elevated atmospheric $\mathrm{CO}_{2}$ concentration on growth and leaf litter decomposition of Quercus acutissima and Fraxinus rhynchophylla. PLoS ONE 2017, 12, e0171197. [CrossRef]

28. Elvidge, C.D. Visible and near infrared reflectance characteristics of dry plant materials. Int. J. Remote Sens. 1990, 11, 1775-1795. [CrossRef]

29. Vane, C.H.; Drage, T.C.; Snape, C.E.; Stephenson, M.H.; Foster, C. Decay of cultivated apricot wood (Prunus armeniaca) by the ascomycete Hypocrea sulphurea, using solid state 13C NMR and off-line TMAH thermochemolysis with GC-MS. Int. Biodeterior. Biodegrad. 2005, 55, 175-185. [CrossRef]

30. Pieristè, M.; Chauvat, M.; Kotilainen, T.K.; Jones, A.G.; Aubert, M.; Robson, T.M.; Forey, E. Solar UV-A radiation and blue light enhance tree leaf litter decomposition in a temperate forest. Oecologia 2019, 191, 191-203. [CrossRef]

31. Wang, Q.; Pieristè, M.; Liu, C.; Kenta, T.; Robson, T.M.; Kurokawa, H. The contribution of photodegradation to litter decomposition in a temperate forest gap and understorey. New Phytol. 2020, 229, 2625-2636. [CrossRef] [PubMed]

32. Ukonmaanaho, L.; Starr, M. The importance of leaching from litter collected in litterfall traps. Environ. Monit. Assess. 2001, 66, 129-146. [CrossRef] [PubMed] 